\title{
Comparing of Technical Skills of Young Football Players According to Preferred Foot
}

\author{
Sinan Bozkurt*, Veysel Kucuk \\ Faculty of Sports Science, Marmara University, Istanbul, Turkey
}

Copyright $@ 2018$ by authors, all rights reserved. Authors agree that this article remains permanently open access under the terms of the Creative Commons Attribution License 4.0 International License

\begin{abstract}
The purpose of this study is to compare technical skills of youth soccer players according to foot preference. A total of 61 amateur football players (Under 15) participated in the study from different clubs of Istanbul. The descriptive statistics and the relationship between the technical skills were examined by using Spearman test and Mann Whitney U test was used for paired comparison of the groups. The level of significance taken into account was $(\mathrm{p}<0.05)$. In conclusion, although there were not statistically significant difference between the left-and right footed players in technical skill tests $(\mathrm{p}>0.05)$, and a negative significant relationship was found between dribbling and juggling and long passing skill tests $(\mathrm{p}<0.05)$ in right-footed players. The present study may contribute to the literature on the specific skills related performance profile of youth football players.
\end{abstract}

Keywords Footedness, Right-left Footed, Football, Young Player, Technical Test, Laterality, Preferred-foot

\section{Introduction}

Human beings use their limbs differently, showing preference for the use of one of the symmetrical parts of the body. This is known as functional asymmetry, which can be defined as the difference in the performance of a human characteristic called body laterality, which is expressed as the use of the preferred symmetric parts of the body: foot, hand, ear or eye [1, 2].

Laterality and/or limb preference is determined by preferential use of unilateral limb in voluntary movements [3]. Elias and Bryden [4] state that cerebral laterality is much more related to footedness than other lateral preferences and less affected by cultural and environmental factors.

Footedness is less affected by social pressures and thus it can be a better indicator of hemispheric specialization than handedness. Furthermore, footedness can be a more precise indicator of specific cognitive and motor performance features. In the general population, estimates of left-foot preference are around $20 \%[5,6]$.
In the soccer domain, systematic training which players are exposed to during their career influences the use of one or both limbs, as the player's decisions are influenced by the specific motor skills proficiency [7].

Using the dominant and recessive feet very well provides important advantages for the football players. Because of this; the importance of bilateral skill trainings for lower extremity in football has increased and footballers' using both of their feet very well has become necessary for them .Learning a motor skill in one limb can transfer to the opposite limb a phenomenon called as interlimb transfer and evidence for interlimb transfer in the lower-extremity is limited and mixed [8, 9].

Football successful performance is a norm requiring an enormous number of capacities and one of them is technique. Football is classified as an invasion game featuring a ball, therefore it is well accepted that technical performance is important for players and teams to achieve success. Technical proficiency is particularly important in the development of young football players. Technical skills including such as long passing, shooting, dribbling, ball control [10, 11, 12, 13]. Moreover, it is often assumed that being equally skilled with both feet (i.e., two-footedness) is an advantage in soccer and a prerequisite for soccer expertise [14].

As far as we know there has been less research on lower limb preference than handedness and also relationship between preferred foot and technical skills of football and compare to left-footed and right-footed players in players. Studying lower limb preference can be a useful measure in understanding the underlying neuromuscular functioning. Therefore, the purpose of this study is to compare technical skills of youth football players according to foot preference.

\section{Material and Methods}

\subsection{Participants}

A total of 61 amateur male football players age of 15 years (Under 15) who played different clubs of Istanbul were selected and were classified into right-footed $(n=31)$ 
height $168.84 \pm 5.05 \mathrm{~cm}$ and body weight $58.63 \pm 7.41 \mathrm{~kg}$, and left-footed $(\mathrm{n}=30)$ height $170.12 \pm 5.38 \mathrm{~cm}$ and body weight $60.75 \pm 6.09 \mathrm{~kg}$, participants who do football training at least four hours in a week.

\subsection{Measurement Protocols}

In this study, dribbling, juggling, long passing and shooting tests were applied for football technical skills with a number 5 ball on grass field.

Dribbling Test: Player started from step position without any signal and run through a slalom course as fast as possible. The time for dribbling were measured by light barrier systems and the better of two attempts counted.

The Juggling Test comprised three parts (total 10 points)

a) juggle the ball only with the left and right foot 10 times without ground contact within 5 meters and 5 meters square area (3 points) b) juggle the ball only with head 10 times within 5 meters and 5 meters square area (3 points), c) juggle the ball free style (head, foot, knee) at distance of 15 meters (4 points).

Shooting Test: Player shooted the ball from distance of 20 meters to the goal $(7,32 \mathrm{~m}$. $\times 2,44 \mathrm{~m}$.) with preferred foot three times. Left and right upper corners of the goal were divided into four parts. The accurate shooting were rated between 1 and 4 points (total 12 points)

Long-passing Test: Player kicked the ball from distance of 34,5 meters to the target field $(5 \mathrm{~m}$. $x 5 \mathrm{~m}$.) with preferred foot three times. The accurate passing were rated between 1 and 4 points (total 12 points)

\subsection{Statistical Analysis}

The descriptive statistics were used as arithmetic means, standart deviations. The relationship between the technical skills were examined by using Spearman test and Mann Whitney U test was used for paired comparison of the groups. The level of statistical significance was set up $(\mathrm{p} \leq 0.05)$. Statistical analyses were performed by using the Statistical Package for Social Sciences (SPSS version 16.0).

\section{Findings}

Table 1. Descriptive Statistics of Players for Technical Skill Components

\begin{tabular}{|c|c|c|}
\hline $\begin{array}{c}\mathrm{n}=61 \\
\text { Technical Skill Components }\end{array}$ & Preferred Foot & Mean $\pm \mathrm{SD}$ \\
\hline \multirow{2}{*}{ Dribbling (seconds) } & Right-footed & $10.46 \pm 0.97$ \\
\cline { 2 - 3 } & Left-footed & $10.58 \pm 1.24$ \\
\hline \multirow{2}{*}{ Shooting (point) } & Right-footed & $3.06 \pm 1.80$ \\
\cline { 2 - 3 } & Left-footed & $3.26 \pm 2.18$ \\
\hline \multirow{2}{*}{ Juggling (repetation) } & Right-footed & $6.77 \pm 0.97$ \\
\cline { 2 - 3 } & Left-footed & $6.86 \pm 2.83$ \\
\hline \multirow{2}{*}{ Log Passing (point) } & Right-footed & $4.16 \pm 3.15$ \\
\cline { 2 - 3 } & Left-footed & $3.33 \pm 3.37$ \\
\hline
\end{tabular}

The findings of this study are presented in the following four tables. The mean and standard deviation values of the players for technical skill components are indicated in Table 1.

Table 2. The Mann Whitney U analysis of dribbling, shooting, juggling and long passing measurements of the right- and left footed players

\begin{tabular}{|c|c|c|c|c|c|}
\hline $\begin{array}{c}\text { Technical Skill } \\
\text { Components }\end{array}$ & Preferred Foot & $\mathbf{X}$ & Ss & $\mathbf{U}$ & $\mathbf{p}$ \\
\hline \multirow{3}{*}{ Dribbling } & Right-footed & 10.46 & 0.97 & 448.000 & 0.806 \\
\cline { 2 - 6 } & Left-footed & 10.58 & 1.24 & & \\
\hline \multirow{2}{*}{ Shooting } & Right-footed & 3.06 & 1.80 & 448.000 & 0.804 \\
\cline { 2 - 6 } & Left-footed & 3.26 & 2.80 & & \\
\hline \multirow{3}{*}{ Juggling } & Right-footed & 6.77 & 2.18 & 439.000 & 0.682 \\
\cline { 2 - 6 } & Left-footed & 6.86 & 2.63 & & \\
\hline \multirow{2}{*}{ Long passing } & Right-footed & 4.16 & 3.15 & 373.000 & 0.373 \\
\cline { 2 - 6 } & Left-footed & 3.33 & 3.37 & & \\
\hline
\end{tabular}

${ }^{*} \mathrm{p}<0.05$

There were not statistically significant difference between the left-and right footed players in technical skill tests $(\mathrm{p}>0.05)$.

Table 3. Correlation of the right-footed players' parameters

\begin{tabular}{|c|c|c|}
\hline \multirow{2}{*}{ Variables } & \multicolumn{2}{|c|}{ Dribbling } \\
\cline { 2 - 3 } & $\mathbf{p}$ & $\mathbf{r}$ \\
\hline Shooting & 0.835 & 0.089 \\
\hline Juggling & $0.044^{*}$ & -0.365 \\
\hline Long pass & $0.003^{*}$ & -0.514 \\
\hline
\end{tabular}

${ }^{*} \mathrm{p}<0.05$

A negative and significant relationship was found between dribbling and juggling $(\mathrm{r}=-, 365, \mathrm{p}<0.05)$ and long passing $(r=-, 514, p<0.01)$ skill tests in right-footed players.

Table 4. Correlation of the left-footed players' parameters

\begin{tabular}{|c|c|c|}
\hline \multirow{2}{*}{ Variables } & \multicolumn{2}{|c|}{ Dribbling } \\
\cline { 2 - 3 } & $\mathbf{p}$ & $\mathbf{r}$ \\
\hline Shooting & 0.470 & -0.137 \\
\hline Juggling & 0.962 & -0.009 \\
\hline Long pass & 0.551 & -0.113 \\
\hline
\end{tabular}

There were not statistically significant relationship between performance of technical skills in left-footed players ( $>0.05)$.

\section{Discussion}

Upon examining the literature, it is observed that while there are studies in which bilateral transfer are addressed in sports branches with right-hand/footed or left-hand/footed, there is a limited number of studies examining the preferred foot that are left-footed and right-footed in football.[15, 16, 17 ] 
The outcome of the reviewed articles suggests that there is a left foot advantage in football and also left-sided athletes enjoy a performance advantage in fencing, table tennis, or baseball. $[18,19]$

In our study, there were no difference in comparing of technical skills of young football players according to preferred foot ( $\mathrm{p}>0.05)$.

Marinsek [20] assessed lateral asymmetry of performance in preschool children and did not find differences between acquisitions of dribbling with upperand lower-extremity. According to Teixeira \& Teixeira [21] no effect of age was detected on leg preference. Analysis of peak foot velocity revealed similar increment of performance of the right and left legs from the ages 6-8 to 10 years. This finding supports the notion of stable magnitude of interlateral asymmetries of performance during motor development. Bozkurt et al. [22] found a positive relationship was found between the hard floor and the right foot and left foot dynamic balance measurements $(p<0.05)$, Teixeira et. al. [23] found similar relationship between the right and left legs of players' body balance stabilization. Yanci and Camara [24] were to assess unilateral and bilateral vertical jump performance characteristics between the dominant and non-dominant leg in male soccer players $(22.80+/-2.71$ years $)$ at their study. In results of the study although differences were found between the dominant and non-dominant leg in the impulse phase of the jump, no significant differences were found between dominant and non-dominant legs in the landing phase of vertical jump variables. The results of these studies are parallel with our study.

On the other hand, although significant relationship was found between dribbling and juggling and pass skills $(\mathrm{p}<0.05)$ in right-footed players, were not statistically significant relationship between performance of technical skills in left-footed players ( $\mathrm{p}>0.05$ ).

\section{Conclusions}

In conclusion, there were not significant difference between left-and right footed players in the technical skills (p>0.05).

The present study may contribute to the literature on the specific skills related performance profile of youth football players. Further studies are recommended to clarify the comparing of technical skills of players according to preferred foot parameters.

\section{Acknowledgements}

The author thanks TFF Meral Celal Aras Sports High School Directorate for their assistance in this study.

\section{Note}

This study was presented as poster announcement at the World Conference on Science and Soccer. Rennes, France on $29^{\text {th }}$ May - 02 June 2017.

\section{REFERENCES}

[1] Teixeira LA, Paroli R. (2000) Assimetrias laterais em accoes motoras: preferencia versus desempenho. Motriz, 6(1):1-8

[2] Fonseca, V. (1988) Psicomotricidade 2nd. ed. São Paulo: Martins Fontes.

[3] Sadeghi, H., Allard, P., Prince, F., Labelle, H. (2000). Symmetry and limb dominance in able-bodied gait: A review (Review). Symmetry and limb dominance in able-bodied gait: A review (Review). Gait and Posture12(1), 34-45

[4] Elias LJ, Bryden MP. (1998). Footedness is a better predictor of language lateralization than handedness. Laterality, 3(1): 41-51.

[5] Nissan J, Gross MD, Shifman A Tzadok L, Assif D. (2004). Chewing side preference as a type of hemispheric laterality. Journal of Oral Rehabilitation, 31: 412-416.

[6] Carey, D. P., Smith, G., Smith, D. T., Shepherd, J. W., Skriver, J., Ord, L., \& Rutland, A. (2001). Footedness in world soccer: An analysis of France'98. Journal of Sports Sciences, 19(11), 855-864. doi:10.1080/026404101753113804

[7] McMorris T., McGillivary, W.W. (1988). Science and Football. E \& FN Spon: 552-557.

[8] Erdil, Guven; Yorulmaz, Hasan; Olcucu, Burcin; Bulbul, Alpay (2016). Effect of 8 weeks bilateral football training program for 11-12 age group children over learning transfer and permanency of the learning transfer. International Journal of Academic Research. 8(5), 18-23.

[9] Chandramouli, K., Rajiv, R., Manik, T. (2017). Interlimb transfer of motor skill learning during walking: No evidence for asymmetric transfer. Gait \& Posture. 56: 24-30.https://doi.org/10.1016/j.gaitpost.2017.04.032

[10] Huijgen BC, Elferink-Gemser MT, Ali A, Visscher C. (2013). Soccer skill development in talented players. Int J Sports Med. 34:720-726.

[11] Stolen T., Chamari K, Castagna C, Wisloff U. (2005). Sports Medicine. 35(6): 501-536.

[12] Höner, O., Votteler, A., Schmid, M., Schultz, Roth, K. (2015). Psychometric properties of the motor diagnostics in the German football talent identification and development programme, Journal of Sports Sciences, 33:2, 145-159, DOI: 10.1080/02640414.2014.928416.

[13] Abdullah,M.R., Musa, R.M., Kosni, N.A., Kosni,N.A., Maliki,A.B.H.M., Zawi, M.M. (2016). Profiling and Distinction of Specific Skills Related Performance and Fitness Level between Senior and Junior Malaysian Youth 
Soccer Players. International Journal of Pharmaceutical Research. 8(3): 64-71

[14] Grouios, G., Kollias, N., Koidou, F., \& Poderi, A. (2002). Excess of mixed footedness among professional soccer players. Perceptual and Motor Skills, 94(2), 695-699. doi:10.2466/pms.2002.94.2.695

[15] Carey, D.P., Smith, D.T., Martin, D., Smith, G., Skriver, J., Rutland, A., Shepherd, J.W. (2009) the bi-pedal ape: Plasticity and asymmetry in footedness. Cortex, 45, 652.

[16] Grouios, G., Kollias, N., Tsorbatzoudis, H., Alexandris, K. (2002) Overrepresentation of mixed-footedness among professional and semi-professional soccer players: an innate superiority or a strategic advantage? Journal of Human Movement Studies, 42: 19-29.

[17] Gentry,V., Gabbard, C.(1995) Foot preference behavior: A developmental perspective. The Journal of General Psychology, 122: 37-45.

[18] Petro, B.MA; Szabo, A. (2016). The Impact of Laterality on Soccer Performance. Strength \& Conditioning Journal. 38(5), 66-74. doi: 10.1519/SSC.0000000000000246

[19] Loffing, F.,Hagemann, N.(2016). Performance Differences between Left- and Right Sided Athletes in One-on-One Interactive Sports. Laterality in Sports Theories and Applications.12, 249-277. doi:10.1016/B978-0-12-801426-4.00012-2

[20] Marinsek, M. (2016). Lateral asymmetry as a function of motor practice type of complex upper- and lower-limb movement in young children. Laterality: Asymmetries of Body, Brain and Cognition.21 (3), 267-281.

[21] Teixeira, M.C.T., Teixeira, L.A. (2008). Leg Preference and Interlateral Performance Asymmetry in Soccer Player Children Developmental Psychobiology. 50(8), 799-806.

[22] Bozkurt, S., Erkut, O., Akkoç, O. (2016). Relationships between Static and Dynamic Balance and Anticipation Time, Reaction Time in School Children at the Age of 10-12 Years. Universal Journal of Educational Research. 5(6), 927 - 931. DOI: 10.13189/ujer.2017.050603

[23] Teixeira, L.A., Oliveira, D.L., Romano, R.G., Correa, S.C. (2011). Journal of Research Quarterly for Exercise and Sport. 82(1). 21-27.

[24] Yanci, J., Camara, J. (2016). Bilateral and Unilateral Vertical Ground Reaction Forces and Leg Asymmetries in Soccer Players. B1ology of Sport. 33 (2) 